\title{
Aula prática para disciplina de Bioquímica abordando a influência dos processos térmicos na atividade de lectinas provenientes de leguminosas
}

\section{Practical class for Biochemistry discipline addressing the influence of thermal processes in the activity of lectins from leguminous plants}

Aline Matté ${ }^{1,2}$, Patrícia Idalina de Lemos Rodrigues ${ }^{1,3}$, Daniela Pereira Stocher ${ }^{1,3}$, Renata Wadenphul de Moraes $^{1,3}$, Ludymila Schulz Barroso ${ }^{1,3}$, Priscila Silva Corrêa ${ }^{1,3}$, Cristiane Matte ${ }^{1,2}$ *

${ }^{1}$ Departamento de Bioquímica, Instituto de Ciências Básicas da Saúde, Universidade Federal do Rio Grande do Sul

${ }_{2}^{2}$ Programa de Pós-Graduação em Ciências Biológicas: Bioquímica, Universidade Federal do Rio Grande do Sul

${ }^{3}$ Curso de Graduação em Nutrição, Faculdade de Medicina, Universidade Federal do Rio Grande do Sul "e-mail: matte@ufrgs.br

\section{Resumo}

Lectinas são proteínas altamente expressas em leguminosas, que possuem a capacidade de reconhecer especificamente e ligar carboidratos, inclusive na membrana celular de eritrócitos. A cocção de alimentos ricos em lectinas, tais como feijão, ervilha e lentilha promovem a desnaturação das proteínas, dentre elas as lectinas, que com a estrutura nativa, perdem a capacidade de interação com as glicoproteínas presentes em membranas. Esse trabalho apresenta o desenvolvimento de um protocolo de aula prática de Bioquímica, de fácil execução e resultados significativos, que permitem a demonstração das propriedades hemaglutinantes presentes na estrutura nativa de lectinas e o efeito desnaturante do calor. Diferentes formas de cocção foram utilizadas, a fim de demonstrar aos graduandos de Nutrição quais metodologias de preparo de alimentos são próprias para o consumo.

Palavras-chave: Nutrição, Lectinas, Estrutura nativa de proteínas

\begin{abstract}
Lectins are proteins highly expressed in leguminous plants, which are capable of specifically recognize and bind carbohydrates, including those found in the erythrocyte membrane. The process of cooking food rich in lectins, such as beans, peas and lentils; promote protein denaturation, losing the native structure, and consequently, the ability of carbohydrate binding. This study presents the development of a protocol for practice classes of Biochemistry, permitting an easy way to verify meaningful results, allowing the demonstration of haemagglutinating properties presented by lectins in their native structure, and lost after food thermic treatment. Different ways of cooking were used in order to demonstrate to Nutrition undergraduate students what methodologies are suitable for consumption.
\end{abstract}

Keywords: Nutrition, Lectins, Proteic native structure 
Aula prática para disciplina de Bioquímica abordando a influência dos processos térmicos na atividade de lectinas provenientes de leguminosas

\section{Ficha da atividade desenvolvida}

Título: Estrutura nativa de proteínas: a influência dos processos térmicos nas propriedades de lectinas provenientes de leguminosas

Público alvo: alunos do curso de nutrição

Disciplinas relacionadas: Bioquímica dos Alimentos

Objetivos educacionais: Demonstrar a presença de lectinas ativas e inativadas pelo calor em alimentos de consumo humano, as leguminosas; demonstrar os fatores que afetam a estrutura nativa e as funções de proteínas.

Justificativa de uso: As lectinas estão presentes na alimentação diária de grande parte da população, e podem causar danos à saúde caso os alimentos não sejam preparados de modo adequado, ou seja, de forma a inativar essas proteínas. Essa aula prática, portanto, aplica um conceito fundamental da Bioquímica, que correlaciona a estrutura nativa de proteínas a suas propriedades/funções, verificando a termoestabilidade das lectinas em leguminosas de consumo humano em um teste rápido de hemaglutinação.

Conteúdos trabalhados: Propriedades e funções das proteínas baseadas em suas estruturas nativas e desnaturadas; fatores que afetam a estrutura nativa de proteínas, especialmente o calor; diferentes formas de cocção de leguminosas e os efeitos sobre a estabilidade térmica das lectinas; adequação dos alimentos ao consumo de acordo com a forma de cocção. 
Aula prática para disciplina de Bioquímica abordando a influência dos processos térmicos na atividade de lectinas provenientes de leguminosas

\section{Introdução}

Lectinas são proteínas não imunológicas que possuem um domínio de reconhecimento de carboidrato, permitindo ligar-se especificamente e reversivelmente a glicídeos por meio de interações químicas não covalentes, tais como ligações de hidrogênio, interações hidrofóbicas e de van der Waal's [1-5]. Os alvos podem ser monossacarídeos ou oligossacarídeos complexos, presentes, por exemplo, na superfície da membrana celular [1-3] . Essa propriedade é a base da capacidade hemaglutinante de lectinas encontradas em diversos organismos, especialmente sementes de plantas leguminosas, como o feijão, a ervilha e a lentilha [1, 3].

Estruturalmente, as lectinas possuem duas a quatro subunidades de 25-30 KDa, com um sítio de ligação a cofatores, tais como $\mathrm{Ca}^{2+}$ e $\mathrm{Mn}^{2+}[3,6]$. A habilidade de reconhecimento específico de carboidratos sugere que as lectinas possam atuar como "receptores" em vegetais, reconhecendo a presença de patógenos e bactérias simbiontes, como as fixadoras de nitrogênio [3, 4]. A capacidade aglutinante das lectinas propicia o seu emprego em inúmeras metodologias de interesse biomédico, tais como o reconhecimento de células sadias e tumorais, purificação de glicoconjugados, bem como atuando como tradutoras do código de açúcares [1, 7, 8]. Por outro lado, essa mesma propriedade pode ter efeitos deletérios sobre as células sanguíneas e da mucosa intestinal, quando os alimentos não forem adequadamente preparados para o consumo, inativando esses fatores antinutricionais $[9,10]$. Os altos níveis de lectinas em feijão-preto (Phaseolus vulgaris L.), que podem alcançar $10 \mathrm{~g} / \mathrm{Kg}$, têm sido associados a sintomas de gastroenterite, diarreia, náuseas, aumento da permeabilidade intestinal e desequilíbrio na flora intestinal em indivíduos que consomem essa leguminosa crua ou mal cozida [9, 10]. Em adição, lectinas da dieta têm sido implicadas no desenvolvimento de diabetes, artrite reumatoide e úlcera péptica [9]. A desnaturação das lectinas presentes no feijão por meio da fervura por ao menos 10 minutos, precedida pelo repouso em água por no mínimo 5 horas tem sido considerado um processo seguro de preparo dessa leguminosa para consumo humano [11].

Proteínas podem sofrer desnaturação por diversos processos que afetam a estabilidade das interações moleculares que determinam sua estrutura nativa, mantida por interações eletrostáticas, ligações de hidrogênio, forças hidrofóbicas e ligações tipo dissulfeto [12, 13]. Tais forças químicas mantém a estrutura nativa das proteínas, que é 
Aula prática para disciplina de Bioquímica abordando a influência dos processos térmicos na atividade de lectinas provenientes de leguminosas

suscetível à desnaturação por ação do calor, alterações de pH do meio, presença de detergentes, sais e solventes orgânicos [12, 14]. A desnaturação de proteínas pelo aquecimento está associada a alterações cooperativas na sua estrutura, sendo que a temperatura no ponto médio desse processo é chamada de temperatura de fusão/desnaturação [14]. Uma vez desnaturadas, as proteínas geralmente perdem a função e, no caso das lectinas, esse fato pode ser verificado pela perda da capacidade de interação com oligossacarídeos presentes na membrana externa de eritrócitos. Assim, lectinas inativas não medeiam hemaglutinação, um fenômeno normalmente evidenciado para lectinas ativas.

Considerando que: (1) a presença de lectinas ativas em leguminosas está associada ao desenvolvimento de lesões em consumidores, (2) existem diferentes protocolos de preparo desses alimentos difundidos entre a população, e (3) lectinas ativas podem ser identificadas por meio de um ensaio de hemaglutinação; o objetivo do trabalho foi elaborar uma aula prática a fim de identificar a presença de lectinas ativas e inativadas pelo calor em diferentes processos de cocção de leguminosas (feijão, ervilha e lentilha), correlacionando os conhecimentos teóricos obtidos na disciplina de Bioquímica dos Alimentos para o curso de Nutrição, com a aplicabilidade desses conceitos na preparação de alimentos para o consumo humano.

\section{Procedimentos experimentais e recursos utilizados no desenvolvimento da aula prática}

\subsection{Animais e reagentes}

Para o desenvolvimento da aula prática foi utilizado um rato Wistar adulto (fêmea, 120 dias de vida), proveniente do Biotério Setorial do Departamento de Bioquímica do Instituto de Ciências Básicas da Saúde (ICBS), da Universidade Federal do Rio Grande do Sul (UFRGS), Porto Alegre, RS, Brasil. O animal foi mantido em condições padrão de alojamento, com ciclo claro/escuro de $12 / 12 \mathrm{~h}$, em temperatura constante de $22 \pm 1^{\circ} \mathrm{C}$ mantida com ar-condicionado. O acesso à água e alimento comercial $(20 \%, \mathrm{~m} / \mathrm{m}$ em proteína) ad libitum foi proporcionado durante toda a vida do animal. Os experimentos foram conduzidos de acordo com as diretrizes nacionais em experimentação animal, normatizadas pela Lei 11.794/2008, Diretriz Brasileira para o Cuidado e a Utilização de Animais para Fins Científicos e Didáticos (DBCA), e Diretrizes da Prática de Eutanásia, 
Aula prática para disciplina de Bioquímica abordando a influência dos processos térmicos na atividade de lectinas provenientes de leguminosas

ambas do Conselho Nacional de Controle de Experimentação Animal (CONCEA/Ministério da Ciência, Tecnologia e Inovação). Esse protocolo de aula prática foi previamente aprovado pela Comissão de Ética no Uso de Animais (CEUA/UFRGS). Todos os cuidados foram tomados a fim de reduzir ou eliminar o desconforto, a dor e o sofrimento animal.

Todos os reagentes químicos foram obtidos da SIGMA Chemical Co. (St. Louis, MO, USA) ou de empresas locais especializadas. As leguminosas foram obtidas de estabelecimentos comerciais em Porto Alegre.

\subsection{Coleta e preparo dos eritrócitos para hemaglutinação}

O rato Wistar foi anestesiado com cetamina $(100 \mathrm{mg} / \mathrm{Kg})$ e xilazina $(10 \mathrm{mg} / \mathrm{Kg})$, administradas por via intraperitoneal. A cavidade torácica foi aberta com auxílio de tesoura cirúrgica e o coração foi exposto. O sangue total foi coletado com ácido etilenodiaminotetracético (EDTA) como anticoagulante, na proporção de $0,1 \mathrm{~mL}$ de EDTA para $5 \mathrm{~mL}$ de amostra, e foi centrifugado à $1.000 \mathrm{xg}$ por $10 \mathrm{~min}$ a $4{ }^{\circ} \mathrm{C}$. $\mathrm{O}$ plasma foi descartado e os eritrócitos, presentes no fundo do tubo, foram lavados por 3 vezes com tampão fosfato-salina $\mathrm{pH} \mathrm{7,4}$. Cada lavagem foi seguida de centrifugação à $1.000 x g$ por 10 min a $4{ }^{\circ} \mathrm{C}$. Os eritrócitos foram coletados e diluídos na proporção 1:5 em tampão fosfato-salina $\mathrm{pH}$ 7,4; sendo armazenados em geladeira por, no máximo, 2 semanas.

Imediatamente antes da aula prática, foi realizada uma nova diluição dos eritrócitos com tampão fosfato-salina pH 7,4, na proporção de 1:3.

\subsection{Preparo das amostras de leguminosas e extração das lectinas}

Inicialmente foram adquiridas as amostras de leguminosas (feijão, lentilha e ervilha) de estabelecimentos comerciais de Porto Alegre.

As amostras foram utilizadas na forma crua (lectinas nativas) e preparadas segundo métodos de cocção amplamente difundidos pela população:

Feijão-preto: 1) cru (FC), 2) coccionado em garrafa térmica (FG), e 3) coccionado em panela de pressão (FP).

Lentilha: 1) crua (LC), 2) coccionada em garrafa térmica (LG), e 3) coccionada em panela de pressão (LP).

Ervilha: 1) crua (EC), 2) coccionada no vapor (EV), e 3) coccionada em panela de pressão (EP). 
Aula prática para disciplina de Bioquímica abordando a influência dos processos térmicos na atividade de lectinas provenientes de leguminosas

\subsubsection{Preparo das amostras de leguminosas}

Leguminosa crua: cinco gramas de cada leguminosa foram pesados e triturados em liquidificador.

Leguminosa coccionada em garrafa térmica: cinco gramas de leguminosa foram pesados e colocados em garrafa térmica com água fervente até cobri-los, overnight ( $\sim$ h). Após, foram triturados em liquidificador, com água do cozimento suficiente para permitir o processo de trituração.

Leguminosa coccionada na panela de pressão: cinco gramas de leguminosa foram pesados e deixados de molho em água morna por $40 \mathrm{~min}$. Após, procedeu-se à fervura em panela de pressão por 40 min, e trituração em liquidificador com água do cozimento suficiente para permitir o processo de trituração.

Ervilha coccionada no vapor: cinco gramas de ervilha coccionada no vapor foram pesados e triturados em liquidificador, com água suficiente para permitir o processo de trituração.

\subsubsection{Extração das lectinas}

Um grama de cada amostra foi pesado em tubo tipo Falcon ${ }^{\circledR}$ com capacidade de 15 $\mathrm{mL}$, e adicionou-se $9 \mathrm{~mL}$ de tampão fosfato-salina $\mathrm{pH} 7,4$. Agitou-se fortemente em agitador de tubos durante 5 minutos, à temperatura ambiente. Centrifugou-se à $2.000 \mathrm{xg}$ durante $20 \mathrm{~min}$ a $4^{\circ} \mathrm{C}$. $\mathrm{O}$ sobrenadante, contendo as lectinas, foi aliquotado em tubos eppendort e armazenado em freezer $-18^{\circ} \mathrm{C}$ até a realização da aula prática.

\subsection{Procedimento de aula prática de identificação da atividade de lectinas em leguminosas por meio de hemaglutinação}

Para a realização da aula prática, os alunos são divididos em duplas e escolhem uma bancada no laboratório para a realização dos ensaios. Cada bancada deve estar equipada com itens de segurança, tais como luvas de procedimentos e coletores de lâminas de vidro para microscopia, bem como pipetas de volume variável e ponteiras de plástico compatíveis. Cada dupla de alunos recebe $100 \mu \mathrm{L}$ de cada amostra de uma leguminosa contendo as lectinas, $100 \mu \mathrm{L}$ de controle negativo (tampão fosfato-salina $\mathrm{pH}$ $7,4), 100 \mu \mathrm{L}$ de controle positivo (amostra de lectinas extraídas de uma leguminosa crua), 
Aula prática para disciplina de Bioquímica abordando a influência dos processos térmicos na atividade de lectinas provenientes de leguminosas

e $500 \mu \mathrm{L}$ de eritrócitos diluídos.

O teste inicia com a identificação das lâminas de microscopia, de acordo com a Figura 1.
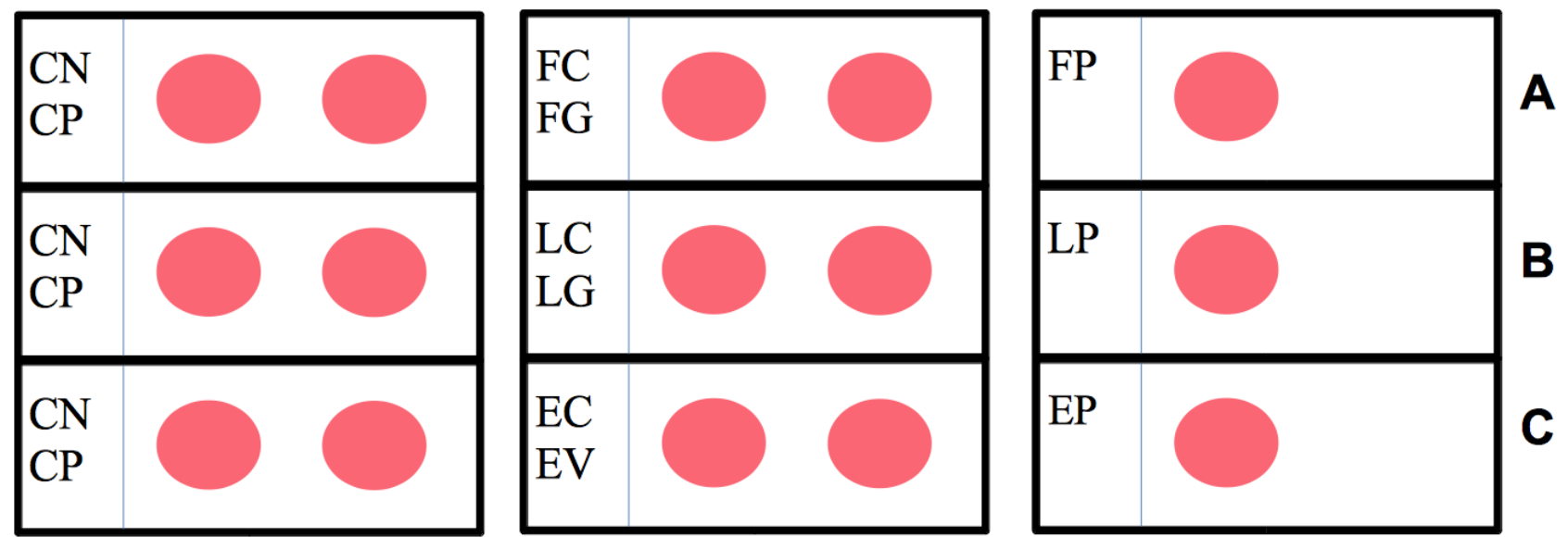

Figura 1. Esquema ilustrativo de identificação das lâminas de microscopia. Em (A) estão representadas as amostras de Feijão, em (B), as amostras de lentilha, e, em (C), as amostras de ervilha; bem como os respectivos controles positivos e negativos utilizados. Abreviaturas: controle negativo (CN), controle positivo $(\mathrm{CP})$, feijão-cru ( $F C$ ), feijão coccionado em garrafa térmica ( $F G)$, feijão coccionado em panela de pressão (FP), lentilha crua (LC), lentilha coccionada em garrafa térmica (LG), lentilha coccionada em panela de pressão (LP), ervilha crua (EC), ervilha coccionada no vapor (EV), e ervilha coccionada em panela de pressão (EP).

Em cada lâmina são pipetados $50 \mu \mathrm{L}$ de cada amostra e controle correspondentes à identificação da lâmina, como demonstrado na Figura 1. Após, procede-se à pipetagem de $50 \mu \mathrm{L}$ de eritrócitos sobre cada amostra, homogeneizando cuidadosamente à amostra previamente pipetada por meio de movimentos de sucção utilizando o primeiro estágio da pipeta; tomando o cuidado de trocar a ponteira a cada pipetagem. As lâminas são deixadas em repouso durante, no mínimo, $15 \mathrm{~min}$ e, ao final, o aluno procede à leitura do resultado. A lâmina deve ser lentamente agitada por meio de movimentos circulares, para visualização da hemaglutinação. Cada uma das amostras deve ser comparada aos controles positivo e negativo, a fim de obter o resultado do teste. Após a análise dos resultados, os alunos preenchem o relatório com a descrição dos resultados e a respectiva discussão.

\section{Resultados esperados}

A Figura 2 é representativa dos resultados obtidos na aula prática. Pode-se verificar que o controle positivo claramente promoveu hemaglutinação, enquanto o controle negativo não, o que pode ser evidenciado pelo aspecto turvo da mistura. $A$ análise de hemaglutinação das amostras demonstrou que as lectinas extraídas de leguminosas 
Aula prática para disciplina de Bioquímica abordando a influência dos processos térmicos na atividade de lectinas provenientes de leguminosas

cruas (feijão, lentilha e ervilha) promoveram a hemaglutinação, como pode ser observado na Figura 2 para o feijão cru. Além disso, as lectinas obtidas de feijão cozido em garrafa térmica mantiveram a atividade hemaglutinante. As demais amostras foram negativas para hemaglutinação, demonstrando que as lectinas foram desnaturadas pelos demais processos de cocção. O feijão coccionado em panela de pressão, a lentilha cozida em garrafa térmica e em panela de pressão não apresentaram hemaglutinação, bem como a ervilha cozida no vapor e em panela de pressão.

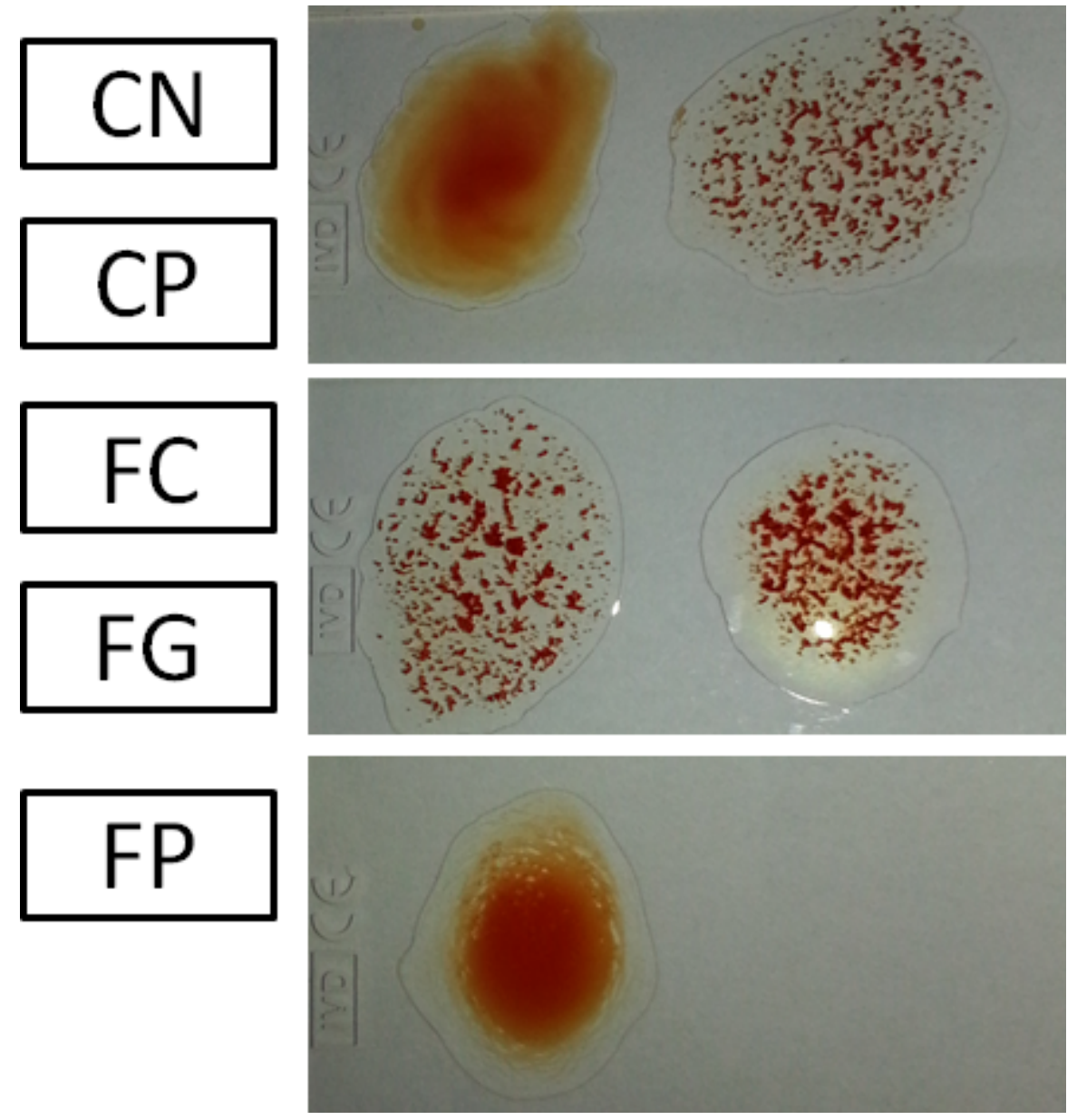

Figura 2. Resultado do ensaio de hemaglutinação realizado para amostras de feijão cru (FC) e coccionado em garrafa térmica ( $F G$ e panela de pressão (FP). Também estão representados os controles negativo (CN) e positivo (CP).

\section{Discussão}

Lectinas encontradas em alimentos de origem vegetal são resistentes à digestão e estão relacionadas a alterações na digestibilidade e valor biológico de proteínas, interferência na absorção de alimentos e inibição do crescimento em animais [15, 16]. Por outro lado, a agressão induzida pelas lectinas sobre o epitélio intestinal pode promover a 
Aula prática para disciplina de Bioquímica abordando a influência dos processos térmicos na atividade de lectinas provenientes de leguminosas

sua escamação e substituição, por induzir a proliferação tecidual, além de induzir a secreção hormonal de insulina e colecistoquinina, promovendo benefícios à saúde [17]. Essas interferências na saúde de humanos e outros animais tornam essas proteínas um modelo interessante para a avaliação de suas propriedades ativas, como hemaglutininas, em aulas práticas de Bioquímica ministradas para a graduação em Nutrição. A atividade hemaglutinante das lectinas está associada às propriedades de ligação em carboidratos específicos expostos na face externa da membrana plasmática de eritrócitos e outras células, como é o caso do epitélio intestinal [17]. Dessa forma, diferentes lectinas têm atividade aglutinante sobre amostras de eritrócitos provenientes de animais específicos. Em nossas avaliações, utilizando eritrócitos provenientes de ratos, as amostras de feijão, ervilha e lentilha cruas foram capazes de promover aglutinação. Sugerimos que a implementação dessa metodologia seja aferida em cada laboratório, se o professor desejar utilizar outras fontes de lectinas ou eritrócitos. Sabe-se, por exemplo, que as lectinas da soja promovem aglutinação em eritrócitos provenientes de coelho, mas não de cabra e bovinos [17].

A realização da aula prática permite ao professor discutir e demonstrar aos alunos as propriedades da estrutura nativa de proteínas, em termos da complexidade e interações químicas que estabilizam os diferentes níveis da estrutura proteica, denominados primário, secundário, terciário e quaternário [12]. Ainda, quais os fatores físicos e químicos que afetam a estabilidade estrutural proteica, tais como $\mathrm{pH}$, temperatura, polaridade de solventes, presença de detergentes e sais [12]; demonstrando o efeito do calor úmido sobre a estabilidade térmica das lectinas. Em termos nutricionais, é importante ressaltar que apesar da perda de função das proteínas, o valor nutricional permanece o mesmo, já que a estrutura primária da proteína permanece inalterada e sua constituição em aminoácidos estará inclusive mais disponível ao sistema digestório.

A aula prática apresentada proporciona duas principais reflexões aos alunos: (1) o processo de cocção dos alimentos altera as propriedades hemaglutinantes das lectinas, o que reflete a perda da estrutura nativa dessas proteínas sob ação do calor; (2) o cozimento de feijão em garrafa térmica, popularmente difundido, não é capaz de inativar as lectinas, não sendo indicado ao consumo. 
Aula prática para disciplina de Bioquímica abordando a influência dos processos térmicos na atividade de lectinas provenientes de leguminosas

\section{Impacto no ensino-aprendizado}

Aulas práticas são essenciais no treinamento de habilidades laboratoriais, tais como utilização de equipamentos de proteção individual, de pipetas e vidrarias, organização da bancada de trabalho, experimentos em grupos de alunos que permitam a divisão de tarefas, compreensão e discussão de resultados práticos que demonstrem fenômenos estudados nas aulas teóricas. Esse protocolo, especificamente, permite a visualização das propriedades das estruturas nativas de proteínas, que podem ser afetadas pelo processamento com fins de alimentação, por meio da aplicação de calor úmido.

O ensaio proposto é de fácil realização e visualização, não necessitando de reagentes ou equipamentos complexos para o seu desenvolvimento. Assim, pode ser aplicado em aulas práticas de Bioquímica Nutricional, e também em outros cursos de graduação, onde a ênfase seja adaptada aos objetivos específicos de cada curso.

\section{Considerações finais}

A aula prática apresentada contribui para a visualização do efeito do calor úmido sobre a atividade e função de proteínas, demonstrando que o aquecimento leva à desnaturação e perda da estrutura nativa e consequentemente da propriedade hemaglutinante das lectinas em leguminosas. Particularizando essa aula ao ensino de Bioquímica para o curso de Nutrição, pode-se ainda concluir que a presença de lectinas ativas no feijão cozido em garrafa térmica, evidenciada pela hemaglutinação dessa amostra, indica que esse processo de cocção, amplamente difundido entre a população, não é adequado e pode representar risco ao consumo desse alimento.

\section{Referências}

[1] Silva MR, Silva MAAP. Fatores antinutricionais: inibidores de proteases e lectinas. Rev Nut 2000; 13(1): 5-9.

[2] Gabius HJ, Andre S, Kaltner H, Siebert HC. The sugar code: functional lectinomics. Biochim Biophys Acta 2002; 1572(2-3): 165-177.

[3] Ambrosi M, Cameron NR, Davis BG. Lectins: tools for the molecular understanding of the glycocode. Org Biomol Chem 2005; 3(9): 1593-1608.

[4] Komath SS, Kavitha M, Swamy MJ. Beyond carbohydrate binding: new directions in plant lectin research. Org Biomol Chem 2006; 4(6): 973-988.

[5] Sharon N, Lis H. The structural basis for carbohydrate recognition by lectins. Adv Exp 
Aula prática para disciplina de Bioquímica abordando a influência dos processos térmicos na atividade de lectinas provenientes de leguminosas

Med Biol 2001; 491: 1-16.

[6] Sharon N, Lis H. How proteins bind carbohydrates: lessons from legume lectins. J Agric Food Chem 2002; 50(22): 6586-6591.

[7] Rudiger H, Gabius HJ. Plant lectins: occurrence, biochemistry, functions and applications. Glycoconj J 2001; 18(8): 589-613.

[8] Gemeiner P, Mislovicova D, Tkac J, Svitel J, Patoprsty V, Hrabarova E, Kogan G, Kozar T. Lectinomics II. A highway to biomedical/clinical diagnostics. Biotechnol Adv 2009; 27(1): $1-15$.

[9] Nasi A, Picariello G, Ferranti P. Proteomic approaches to study structure, functions and toxicity of legume seeds lectins. Perspectives for the assessment of food quality and safety. J Proteomics 2009; 72(3): 527-538.

[10] Kumar S, Verma AK, Das M, Jain SK, Dwivedi PD. Clinical complications of kidney bean (Phaseolus vulgaris L.) consumption. Nutrition 2013; 29(6): 821-827.

[11] Venter FS, Thiel PG. Red kidney beans - to eat or not to eat? S Afr Med J 1995; 85(4): 250-252.

[12] Nelson DL, Cox MM. Princípios de Bioquímica de Lehninger. 6a ed. Porto Alegre: Artmed; 2014.

[13] Voet D, Voet JG, Pratt CW. Fundamentos de Bioquímica: a vida em nível molecular. $4^{\mathrm{a}}$ ed. Porto Alegre: Artmed; 2014.

[14] Voet D, Voet JG. Bioquímica. 4ª ed. Porto Alegre: Artmed; 2013.

[15] Grant G, Alonso R, Edwards JE, Murray S. Dietary soya beans and kidney beans stimulate secretion of cholecystokinin and pancreatic digestive enzymes in 400-day-old Hooded-Lister rats but only soya beans induce growth of the pancreas. Pancreas 2000; 20(3): 305-312.

[16] Bouchenak M, Lamri-Senhadji M. Nutritional quality of legumes, and their role in cardiometabolic risk prevention: a review. J Med Food 2013; 16(3): 185-198.

[17] Csaky I, Fekete S. Soybean: feed quality and safety. Part 1: biologically active components. A review. Acta Vet Hung 2004; 52(3): 299-313.

\section{Agradecimentos}

Agradecemos à inestimável contribuição da Professora Magdolna Maria Vozari Hampe, que, por diversas ocasiões, elucidou nossas dúvidas a respeito das lectinas, suas propriedades e métodos de extração. Também agradecemos ao essencial apoio técnico de Fernanda Timm Seabra Souza, Geancarlo Zanatta, Luiz Paulo da Silva Braga e Norma Helena Silva da Silva, que auxiliaram na preparação das aulas práticas aplicadas aos alunos da nutrição. 